\title{
Laser-based powder bed fusion of niobium with different build-up rates
}

\author{
Tjorben Griemsmann $^{1}$ (D) $\cdot$ Arvid Abel $^{1} \cdot$ Christian Hoff $^{1} \cdot$ Jörg Hermsdorf ${ }^{1} \cdot$ Markus Weinmann $^{2} \cdot$ Stefan Kaierle $^{1}$
}

Received: 17 September 2020 / Accepted: 13 January 2021 / Published online: 12 March 2021

(C) The Author(s) 2021

\begin{abstract}
Niobium is an important material for high temperature applications, in space, in superconductors or in chemical process constructions. Laser-based powder bed fusion of niobium (PBF-LB/M/Nb) offers new opportunities in design, though it is still an expensive technique. The build-up rate is an important factor for economical manufacturing using PBF-LB/M/Nb. It is largely influenced by variation of process parameters, affecting the heat flow during the manufacturing process. In this work, an empirical model for PBF-LB/M/Nb is developed. Based on this model, manufacturing parameter sets using different volume build-up rates are predicted and confirmed. They enable the manufacture of parts with homogeneous and crack-free microstructure with more than $99.9 \%$ relative density. Tensile and hardness tests of specimens, which were manufactured using different parameter sets, are performed to determine the effects of the build-up rate-and thus the heat flow during manufacturing - on different mechanical properties. The ultimate tensile strength and yield strength of as-manufactured specimens reach values up to $525 \mathrm{MPa}$ and $324 \mathrm{MPa}$, respectively, while the elongation at break ranges between approximately 8 and 16\%. The Vickers hardness of all specimens was in the range of $149 \pm 8 \mathrm{HV} 0.1$. In addition, the microstructure of the manufactured samples is investigated by means of light as well as scanning electron microscopy.
\end{abstract}

Keywords Laser-based powder bed fusion · Niobium $\cdot$ Mechanical properties · Design of experiments

Abbreviations
$\mathrm{BEC}$
$b_{\mathrm{r}}$
$\mathrm{EBSD}$

EBSD

$h$

PBF-LB/M/Nb

$P$

$t$

$\mathrm{pc}$

SEI

SEM

$v$

UTS

Tjorben Griemsmann

t.griemsmann@1zh.de

1 Laser Zentrum Hannover e.V., Hollerithallee 8, 30419 Hannover, Germany

2 TANIOBIS GmbH, Im Schleeke 78-91, 38642 Goslar, Germany

$\begin{array}{ll}E_{\mathrm{V}} & \text { Volume energy } \\ \text { YS } & \text { Yield strength }\end{array}$

\section{Introduction}

Niobium belongs to the group of refractory metals, which are characterized by a high resistance to electrochemical corrosion, high temperature strength and good electrical and heat conducting properties [1]. The major consumer of niobium is the steel industry, where it is used as an alloying element to improve the welding behaviour, the heat resistance and the yield and tensile strength [2]. Applications for pure niobium are also in the electronic industry, i.e. capacitors [3-5], in superconductors due to the high superconducting transition temperature [6-8], in the chemical process industry due to the high corrosion resistance [9] and the low thermal neutron capture cross-section [10] makes it suitable to control nuclear reactions. Other upcoming usages are as a bio inert material for medical devices and as absorber for gases in vacuum technology [11]. Niobium is highly ductile and accordingly easy to process by means of machining, forging, drawing etc. A relatively 
new approach to manufacturing niobium and niobium-based alloys is additive manufacturing, also referred to as $3 \mathrm{D}$ printing. Laser-based powder bed fusion, also known as Selective Laser Melting, is a powder bed-based additive manufacturing technique for metals. For the manufacturing process, the CAD model is sliced virtually with a specific thickness. To manufacture one layer, powder with the layer thickness is coated above the previous layer and selectively melted by a laser beam. The process repeats until the part is finished. PBF-LB/M/Nb offers many advantages compared to conventional manufacturing technologies. The major advantages are the freedom in designing complex parts like lightweight structures, contoured cooling channels and the economic benefit in the manufacture of individual components [12]. Moreover, metals or metal alloys with very high melting points such as niobium, tantalum or tungsten, which cannot be cast, could be processed into complex parts without constraints. There are several research groups working on the manufacturing process of niobium alloys with PBF-LB/M [13-18], but only one group is processing pure niobium. They produced a porous coating from niobium with PBF-LB/M/Nb. It is reported about difficulties to melt the powder completely, due to the high melting point of $2468^{\circ} \mathrm{C}$, and therefore to create a dense layer [19]. In addition, there is a research group around Terrazas et al. working on fabricating pure niobium through Electron Beam Melting. Relative densities up to $99.7 \%$ could be achieved. The ultimate tensile strength (UTS) and yield strength (YS) are with $225 \mathrm{MPa}$ and $140 \mathrm{MPa}$ in mean slightly higher and the elongation at break (34\%) is slightly lower than that of conventionally wrought niobium (UTS $=205 \mathrm{MPa}$, $\mathrm{YS}=135 \mathrm{MPa}$ and elongation at break $=45 \%)[20,21]$. However, the manufacturing costs with additive technologies are still relatively high. A large proportion of the costs arises from the expensive plant technology. Therefore, the economics could be improved by manufacturing parameters which enable faster throughput thereby increasing the build-up rate. Higher build-up rates will lead to shorter laser powder interaction times and a change in heat flow and cooling rate of the specimen, due to a faster moving heat source, respectively laser beam. Because the general cooling rate during the $\mathrm{PBF}-\mathrm{LB} / \mathrm{M} / \mathrm{Nb}$ process has a big impact on the microstructure and consequently on the mechanical properties [22-26], it is assumed that different manufacturing parameters could result in different mechanical properties, as shown in [27] for stainless steel and laser powers of $400 \mathrm{~W}$ and $1000 \mathrm{~W}$. The aim of this paper is to investigate the impact of the heat flow and thermal gradients on the microstructure and the mechanical properties of niobium through different build-up rates. For this purpose, several PBF-LB/M parameter sets are explored to manufacture pure niobium parts with densities above $99.9 \%$. Using design of experiments (DoE) techniques, an empirical model for the achieved relative density is developed and validated to derive parameters which are resulting in high densities and different build-up rates. The hypothesis of changing properties by a variation of the heat flow is verified by tensile tests, hardness tests and a discussion of the microstructure.

\section{Materials and methods}

The powder used for the investigations was a gas atomized pure niobium powder (AMtrinsic ${ }^{\circledR}$ Spherical Niobium, Taniobis $\mathrm{GmbH})$ of the sieve fraction 10 to $63 \mu \mathrm{m}(\mathrm{D}(0.10)$ : $22.37 \mu \mathrm{m}, \mathrm{D}(0.50): 39.42 \mu \mathrm{m}, \mathrm{D}(0.90): 65.97 \mu \mathrm{m}$, measured by laser light scattering) which has been obtained using EIGA techniques $($ EIGA = Electrode Induction-melting Gas Atomization). The oxygen level was $556 \mathrm{ppm}$, tap density was $5.56 \mathrm{~g} / \mathrm{cm}^{3}$ and Hall Flow $\left(0,1^{\prime}\right)$ was $12 \mathrm{~s}$. Full analytical details are provided in the product data sheet which is available online [28]. To investigate the morphology of the powder, scanning electron microscope (SEM) images, using a Quanta 400 FEG (FEI Thermo Fisher Scientific, USA), were recorded of the powder at different magnifications as shown in Fig. 1. Powder bed SEM images and polished cross-sections show that most particles exhibit a perfectly spherical shape. Only a negligible number of particles has irregular, i.e. non-spherical surfaces. In few cases, satellite particles are visible which adhere to larger spheres. The polished cross-section of embedded powders demonstrates a more or less perfect density and homogeneity of the powder particles. Voids, cracks or segregations are hardly visible in secondary electron imaging (SEI), Fig. 1(c) or backscattered electron composition (BEC) imaging. The BEC image in Fig. 1(d) not only confirms the findings of the SEI image but it also visualizes crystal sizes and orientations within the spherical particles. The PBF-LB/M/Nb processes were carried out using an additive manufacturing system TruPrint 1000 (Trumpf GmbH \& Co. KG; Germany). The additive manufacturing system was equipped with an ytterbium fiber laser used in continuous wave mode with a maximum power of $170 \mathrm{~W}$ and a wavelength of $1070 \mathrm{~nm}$. The optics included a galvanometric scanner and an $\mathrm{f}$ theta lens, which created a focus diameter of $30 \mu \mathrm{m}$ on the working level. The maximum build space was $100 \mathrm{~mm}$ in diameter and $80 \mathrm{~mm}$ in height. The oxygen content of the building chamber was reduced to $200 \mathrm{ppm}$ by the use of argon as an inert gas.

\subsection{Experimental methods}

In a first step, an empirical model for the relative density as a function of the PBF-LB/M parameters laser power P, 
Fig. 1 SEM images of the used AMtrinsic ${ }^{\circledR}$ Spherical Niobium powder at $\times 250$ a and $\times 500 \mathbf{b}$ magnification. SEI $\mathbf{c}$ and BEC d images of a polished cross-section of resin-embedded powder at $\times 100$ and $\times 1500$ magnification, respectively


scanning speed $\mathrm{v}$ and hatch spacing $\mathrm{h}$ was constructed to determine different process parameter combinations (pc), which led to high relative densities in the manufactured part. For this purpose, cubes with an edge length of $5 \mathrm{~mm}$ were manufactured on 2-mm support structures. All specimens were built with a layer thickness of $20 \mu \mathrm{m}$, a rotation of $15^{\circ}$ around the $z$-axis and chess pattern with a squared maximum field size of $4 \mathrm{~mm}$ and a $25-\mu \mathrm{m}$ distance between the fields. The fields were filled with an unconnected zigzag pattern as illustrated in Fig. 2. Each layer was rotated with an increment angle of $90^{\circ}$ and shifted by $1 \mathrm{~mm}$ in $y$ and $x$ direction. Accordingly every fourth layer had the same hatching strategy. The powder feed rate was kept constant at $220 \%$ and the oxygen content below $200 \mathrm{ppm}$. No contour scans were done to reduce the factors, which have an influence on the relative density, and the amount of required trials. The values for the input variables were chosen through a DoE approach to reduce the necessary trials. In this case, a central composite design was used. In this type of design, the variable matrix is set in the shape of a 'cube' and a 'star'. As demonstrated in Fig. 3, the manufactured parameter sets were the value combinations in the corners of the cube and in the additional star points with the centre point. The values are given in Table 1. It was important that every combination led to a successfully built specimen with a measurable relative density. For this reason, the choice of the parameter limits was based on pre trials. With each parameter set resulting from the 'cube' matrix, two specimens were manufactured. The centre point of the 'star' matrix was used for manufacturing specimens eight times and the outer points two times. In sum, 36 specimen were manufactured in one PBF$\mathrm{LB} / \mathrm{M} / \mathrm{Nb}$ process. The whole process is carried out twice to involve reproducibility. The predicted empirical model is a mathematical approximation. The model was confirmed by building additional test samples, which should theoretically lead to high relative densities. To evaluate the influence of the built-up rate on the mechanical properties, confirmed parameter combinations were chosen to manufacture test specimen for tensile tests according to DIN 50125. For each combination, three specimens were manufactured orientated in building direction.

\subsection{Methods for analysis}

The 'cube' specimens were embedded in epoxy and crosssections of two parallel levels created to evaluate the relative density. Images of the cross-sections were taken using a light microscope (Olympus BX60) with a magnification of five and a microscope camera (Zeiss AG AxioCam $\mathrm{MRc})$. The images were processed with a computer vision application using OpenCV. The application detects the 
Fig. 2 Schematic illustration of the scanning paths in each consecutive layer
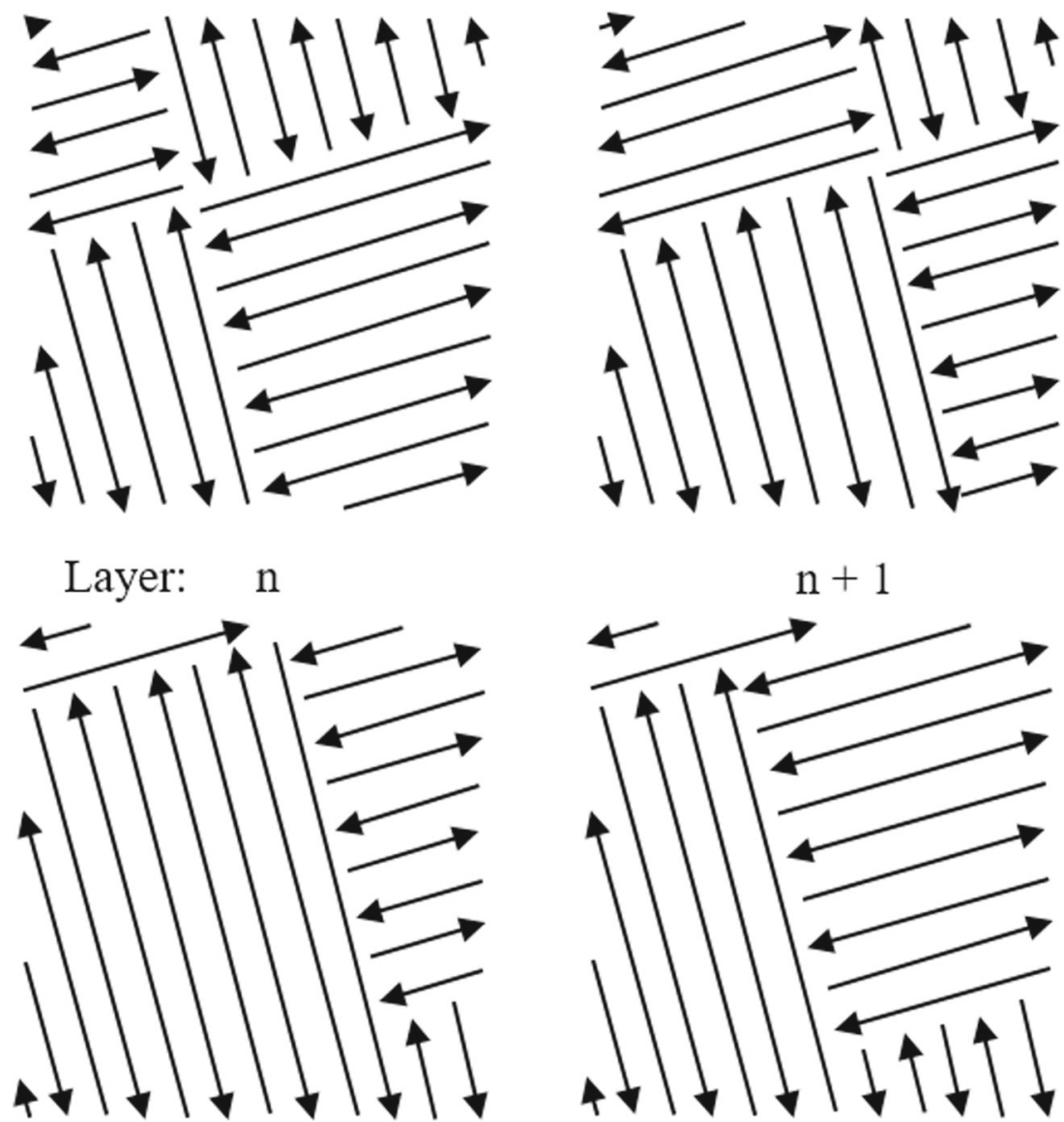

$n+2$

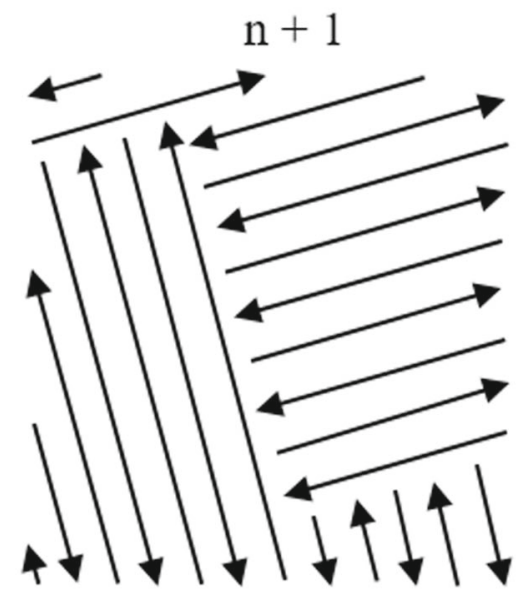

$\mathrm{n}+3$ contours of the specimen and the pores based on colour differences as shown in Fig. 4. The relative density was calculated by setting the sum of the areas determined as

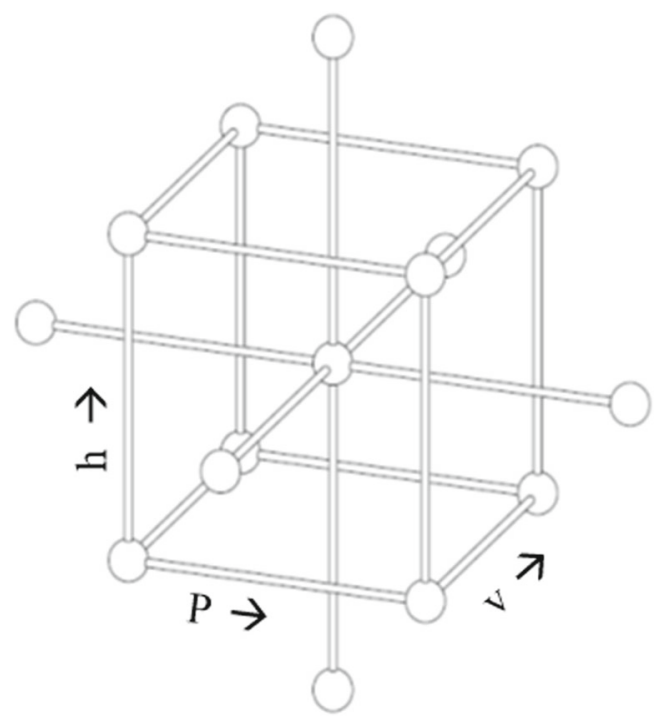

Fig. 3 Schematic illustration of a central composite design. Each dot marks a parameter combination pores (red lines in Fig. 4) in relation to the area determined as the specimen (green line in Fig. 4), according to Eq. 1.

Rel.Density $=\left(1-\frac{\sum \text { Area }_{\text {pores }}}{\text { Area }_{\text {CrossSection }}}\right) \cdot 100 \%$

Based on the calculated values, a mathematical model using the statistics software JMP (SAS Institute) was fitted to describe the relative density as a function of laser power, scanning speed, hatch spacing and second orders of the variables or interactions between them. Only high significant $(p$ value $<0.0001)$ influences were used for the regression. The mathematical model was used to

Table 1 Values for the input variables in the central composite design

\begin{tabular}{lccccc}
\hline & Star 0 & Cube 0 & Centre & Cube 1 & Star 1 \\
\hline $\begin{array}{l}\text { Laser power } P \\
\text { in W }\end{array}$ & 90 & 110 & 130 & 150 & 170 \\
$\begin{array}{l}\text { Scanning speed } \\
v \text { in mm/s }\end{array}$ & 500 & 750 & 1000 & 1250 & 1500 \\
$\begin{array}{l}\text { Hatch spacing } \\
h \text { in } \mu \mathrm{m}\end{array}$ & 20 & 40 & 60 & 80 & 100 \\
\hline
\end{tabular}


calculate 84 parameter combinations, which should lead to relative densities above $99.9 \%$ in theory. The parameter combinations were used to build cubic specimens two times and the mathematical model was updated with the measured relative densities to achieve a better approximation. The build-up rate $B_{\mathrm{r}}$ and volume energy $E_{\mathrm{V}}$ of the parameter combinations were calculated according to Eqs. 2 and 3 [29] where $t$ is the layer thickness. For the build-up rate, the time needed for recoating, jumps, acceleration and deceleration of the scanner was not considered. The volume energy is related to the hatch spacing and the thickness of one layer.

$$
B_{\mathrm{r}}=v \cdot h \cdot t
$$

$E_{\mathrm{V}}=\frac{P}{v \cdot h \cdot t}$

A set of specimens manufactured with parameter combinations with different build-up rates, which led to high relative densities, were prepared for hardness testing. For the evaluation, a Nexus 4000 (Innovatest, Netherlands) was used and the HV0.1 Vickers hardness determined according to DIN EN ISO 6507-1:2018 applying an indentation force of $0.981 \mathrm{~N}$. The hardness was correlated with the energy input and the built-up rates of the specimens to detect trends or significances. The tensile specimens were tested with the tensile testing machine Landmark 370.10 (MTS, USA). The machine elongates the specimen until it fractures. The applied force was recorded together with the elongation to compare the different built-up rates. To determine the fracture mechanism, SEM images of the fracture surface were taken and interpreted. To generate an understanding, how the build-up rate or volume energy influences

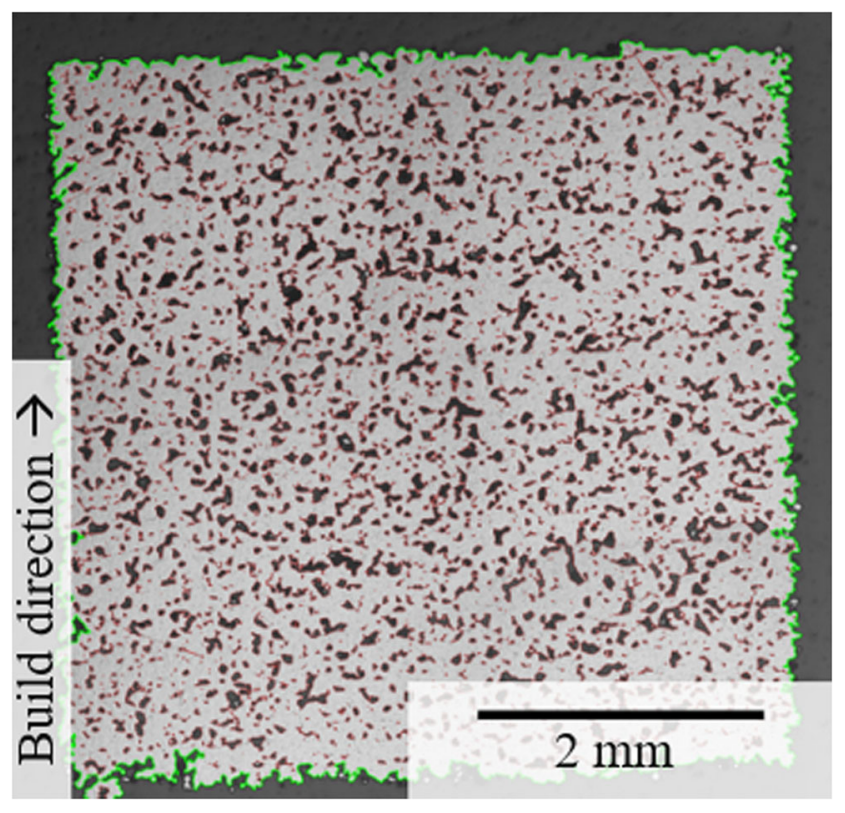

Fig. 4 Example of a cross-section; contour of the specimen (green line) and contours of the pores (red lines) the microstructure cross-sections were etched with a mixture of nitric acid, hydrochloric acid and hydrofluoric acid. The grains were investigated via the light microscope and for a more detailed insight through electron backscatter diffraction (EBSD).

\section{Results and discussion}

\subsection{Empirical model}

All cubic specimens were successfully built without obvious defects on the surface. The relative densities of the specimens had the lowest value with $81.55 \pm 0.37 \%$ for the parameter combination of $P=110 \mathrm{~W}, v=1250 \mathrm{~mm} / \mathrm{s}$ and $h=80 \mu \mathrm{m}$. The highest density value was determined with $99.74 \pm 0.05 \%$ for $P=150 \mathrm{~W}, v=750 \mathrm{~mm} / \mathrm{s}$ and $h=80 \mu \mathrm{m}$. The cross-section of the best specimen is shown in Fig. 5 . The relative densities of all $72(2 \times 36)$ specimens of the central composite design were used for the mathematical approximation to determine the relative density as a function of the laser power, scanning speed and hatch spacing. Only highly significant values $(p$ value $<0.0001)$ were used for the regression given in Eq. 4. The regression equation is only valid in the range of the central composite design given in Table 1. Based on Eq. 4, greymaps with fixed hatch spacing in $5-\mu \mathrm{m}$ steps from 30 to $95 \mu \mathrm{m}$ were created. An example $(h=65 \mu \mathrm{m})$ is given in Fig. 6. Based on these greymaps parameter combinations in the area of relative densities $>99.9 \%$ were chosen in steps of $10 \mathrm{~W}$ for the laser power and $250 \mathrm{~mm} / \mathrm{s}$ for the scanning speed to confirm the

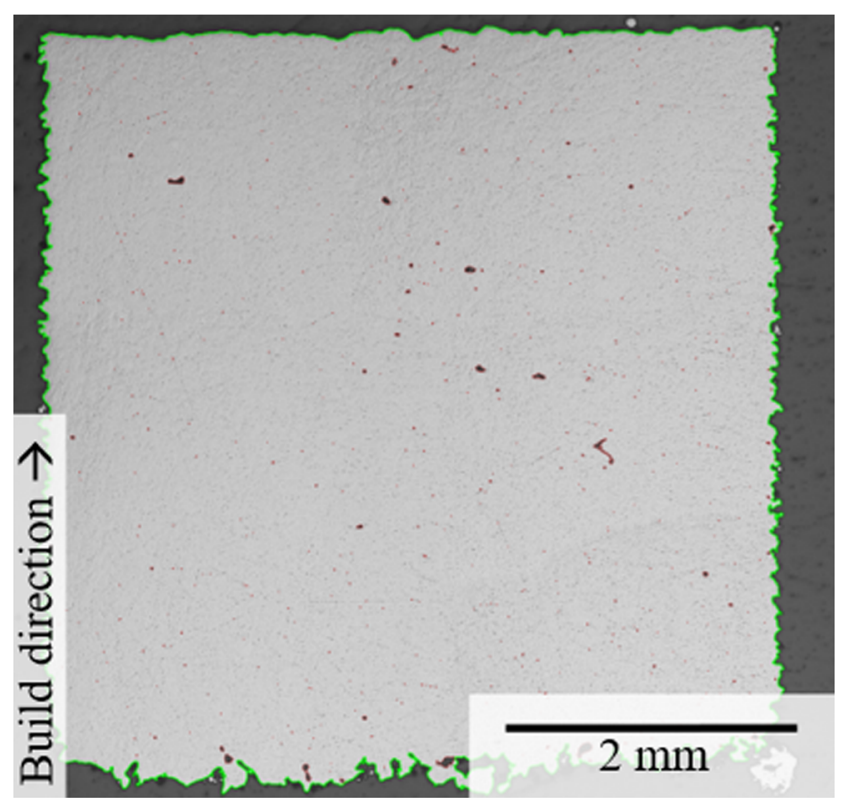

Fig. 5 Cross-sections of the specimen with the highest density $(P=150 \mathrm{~W}, v=750 \mathrm{~mm} / \mathrm{s}$, and $h=80 \mu \mathrm{m})$ 


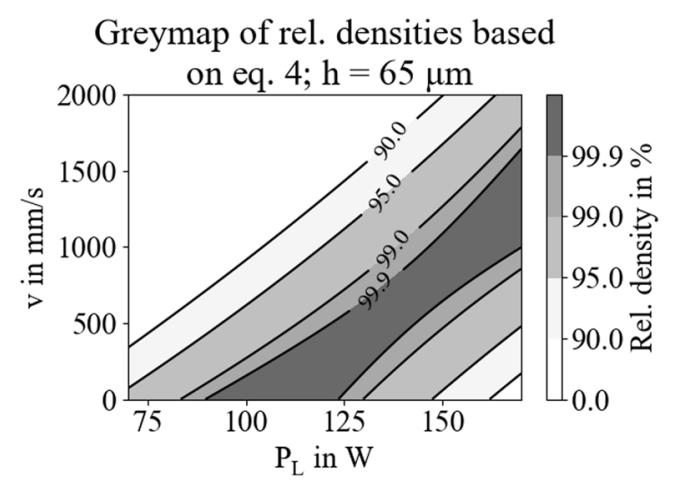

Fig. 6 Greymap of Eq. 4. The plot represents the regression based on the 72 specimens of the central composite design. The hatch spacing is fixed to $65 \mu \mathrm{m}$

model. To extend the range of the empirical model, also extrapolated parameter combinations with a scanning speed of $250 \mathrm{~mm} / \mathrm{s}$ were considered. This resulted in 84 parameter combinations for confirmation trials.

$$
\begin{aligned}
& \operatorname{Rel} . D .(P, v, h) \\
= & -3.6 \cdot 10^{-3} \frac{\%}{W^{2}} \cdot P^{2}-8.1 \cdot 10^{-6} \frac{\% \cdot s^{2}}{\mathrm{~mm}^{2}} \cdot v^{2} \\
& -2.3 \cdot 10^{-3} \frac{\%}{\mu m^{2}} \cdot h^{2}+369 \cdot 10^{-6} \frac{\% \cdot s}{\mathrm{~W} \cdot \mathrm{mm}} \cdot P \cdot v \\
& -150 \cdot 10^{-6} \frac{\% \cdot s}{\mathrm{~mm} \cdot \mu \mathrm{m}} \cdot v \cdot h+760.5 \cdot 10^{-3} \frac{\%}{\mathrm{~W}} \cdot P \\
& -31.6 \cdot 10^{-3} \frac{\% \cdot s}{\mathrm{~mm}} \cdot v+449 \cdot 10^{-3} \frac{\%}{\mu \mathrm{m}} \cdot h+41.1 \%
\end{aligned}
$$

The lowest density value out of the 84 confirmation specimens was $97 \%$ for the parameters $P=170 \mathrm{~W}, v=1500$ $\mathrm{mm} / \mathrm{s}$ and $h=35 \mu \mathrm{m}$. Eighteen out of the 84 predicted and tested parameter combinations exhibited a relative density $>99.9 \%$; they are listed in Table 2. The build-up rates ranged from $0.33 \mathrm{~mm}^{3} / \mathrm{s}$ (pc 1) to $1.63 \mathrm{~mm}^{3} / \mathrm{s}$ (pc 4) which is about five times this value. The volume energy was calculated for pc 1 to $400 \mathrm{~J} / \mathrm{mm}^{3}$, which is about four times higher than that of pc 4 which accounted to $104.6 \mathrm{~J} / \mathrm{mm}^{3}$. The regression from Eq. 4 was updated using the results of the 84 confirmation specimen and is therefore even more precise in predicting parameter combinations with high relative densities than before. The new regression is given in Eq. 5 and is illustrated as a greyrmap in Fig. 7. As shown in Eq. 5, the variables laser power $P$, scanning speed $v$ and hatch spacing $h$ have a negative quadratic effect on the relative density. There is a maximum in relative density for each variable, but it shifts if another variable is changed. That is because the variables interact with each other as shown in the terms with $P \bullet v$ and $v \bullet h$. Due to the high number of different pc resulting in high relative densities, the DoE approach with approximation of a mathematical model has been considered suitable for this process development.

$$
\begin{aligned}
& \text { Rel.D. }(P, v, h) \\
= & -3.4 \cdot 10^{-3} \frac{\%}{W^{2}} \cdot P^{2}-8.9 \cdot 10^{-6} \frac{\% \cdot s^{2}}{\mathrm{~mm}^{2}} \cdot v^{2} \\
& -2.1 \cdot 10^{-3} \frac{\%}{\mu m^{2}} \cdot h^{2}+344 \cdot 10^{-6} \frac{\% \cdot s}{\mathrm{~W} \cdot \mathrm{mm}} \cdot P \cdot v \\
& -90 \cdot 10^{-6} \frac{\% \cdot s}{\mathrm{~mm} \cdot \mu \mathrm{m}} \cdot v \cdot h+732.2 \cdot 10^{-3} \frac{\%}{\mathrm{~W}} \cdot P \\
& -31.1 \cdot 10^{-3} \frac{\% \cdot \mathrm{s}}{\mathrm{mm}} \cdot v+359 \cdot 10^{-3} \frac{\%}{\mu \mathrm{m}} \cdot h+46.1 \%
\end{aligned}
$$

\subsection{Microstructure}

Light microscope images of etched cross-sections of manufactured specimens were prepared to obtain information on grain growth and orientation as a function of process parameters and scanning paths. The examples given in Fig. 8, i.e. pc 17 (a) and pc 14 (b) revealed two types of grain growth, depending on the sectioned scanning paths. Figure 8(a) shows a cross-section of a specimen which is obtained by utilization of zigzag scan vectors in each consecutive layer. The left side of the cross-section, which is graphically separated by a red line from the right to one-third of the image, indicates a vertical columnar grain orientation. Here, the laser beam moved nearly perpendicular to the image plane, as indicated by the $x$ and $\bullet$ icons in the upper figure part. In contrast, in the section on the right side of Fig. 8(a), a wave-type triangular crystal orientation is observed. The distance between a wave maximum and the minimum was $310 \mu \mathrm{m}$, which is approximately the distance between the middle of two neighboured melt tracks, taking the rotation of $15^{\circ}$ around the $z$-axis and a hatch spacing of $85 \mu \mathrm{m}$ in mind (compare with Fig. 2). The grains are orientated in direction of the main heat conduction, which points in a direction between the negative build direction and the negative scanning direction [23]. So, it can be assumed that the zigzag pattern resulted in a negative or positive slope of the wave-type grains, depending on the direction of the scanning track. A schematic illustration of the shape origin is given in Fig. 9, where the heat conductions of two neighboured scanning tracks are modelled as bars and cut in the angle of the cross-section. Figure 8(b) corresponds to a specimen which was obtained by application of zigzag scan vectors with alternating $x y$-orientation, like the most of the investigated specimens. The scanning paths rotated at least every second layer by $90^{\circ}$. Therefore, the grain growth appeared less ordered compared with that shown in subfigure (a). A difference in the microstructure was not observed between the compared pc, only the alignment oft the scanning paths had an influence in this investigation. 
Table 2 Build-up rates and volume energy for pc with relative densities above $99 \%$

\begin{tabular}{|c|c|c|c|c|c|c|}
\hline $\begin{array}{l}\text { Parameter com- } \\
\text { bination pc }\end{array}$ & $\begin{array}{l}\text { Laser power } P \text { in } \\
\mathrm{W}\end{array}$ & $\begin{array}{l}\text { Scanning speed } \\
v \text { in } \mathrm{mm} / \mathrm{s}\end{array}$ & $\begin{array}{l}\text { Hatch spacing } h \\
\text { in } \mu \mathrm{m}\end{array}$ & $\begin{array}{l}\text { Relative density } \\
\text { in } \%\end{array}$ & $\begin{array}{l}\text { Build-up rate } B_{\mathrm{r}} \\
\text { in } \mathrm{mm}^{3} / \mathrm{s}\end{array}$ & $\begin{array}{l}\text { Volume energy } \\
E_{\mathrm{v}} \text { in } \mathrm{J} / \mathrm{mm}^{3}\end{array}$ \\
\hline 1 & 130 & 250 & 65 & 99.90 & 0.33 & 400.0 \\
\hline 2 & 130 & 500 & 65 & 99.92 & 0.65 & 200.0 \\
\hline 3 & 140 & 500 & 65 & 99.94 & 0.65 & 215.4 \\
\hline $4^{*}$ & 170 & 1250 & 65 & 99.94 & 1.63 & 104.6 \\
\hline 5 & 130 & 500 & 70 & 99.94 & 0.70 & 185.7 \\
\hline 6 & 150 & 750 & 70 & 99.92 & 1.05 & 142.9 \\
\hline $7 *$ & 110 & 250 & 75 & 99.95 & 0.38 & 293.3 \\
\hline 8 & 120 & 250 & 75 & 99.94 & 0.38 & 320.0 \\
\hline 9 & 130 & 250 & 75 & 99.94 & 0.38 & 346.7 \\
\hline $10 *$ & 130 & 500 & 75 & 99.97 & 0.75 & 173.3 \\
\hline 11 & 150 & 750 & 75 & 99.92 & 1.13 & 133.3 \\
\hline 12 & 110 & 250 & 80 & 99.94 & 0.40 & 275.0 \\
\hline $13 *$ & 120 & 250 & 80 & 99.96 & 0.40 & 300.0 \\
\hline 14 & 140 & 500 & 80 & 99.92 & 0.80 & 175.0 \\
\hline 15 & 150 & 750 & 80 & 99.93 & 1.20 & 125.0 \\
\hline $16^{*}$ & 110 & 250 & 85 & 99.94 & 0.43 & 258.8 \\
\hline 17 & 120 & 250 & 85 & 99.91 & 0.43 & 282.4 \\
\hline 18 & 130 & 250 & 85 & 99.91 & 0.43 & 305.9 \\
\hline
\end{tabular}

*Parameter combinations chosen for tensile tests

The EBSD image displayed in Fig. 10 represents a clip which typically appears in areas with triangular wave-type grain growth mentioned above with three different orientations. Axis 2 (A2) corresponds to the orientation with respect to the build direction and a mixture of 001 alignment on the connection of the triangular wave-type grains and a strong 111 alignment between the connection lines. The 001 alignment was also observed in the transverse (axis 1) and normal (axis 3 ) direction, but less intense. The texture between the 001 alignment in A1 and A3 was mainly orientated in 101.

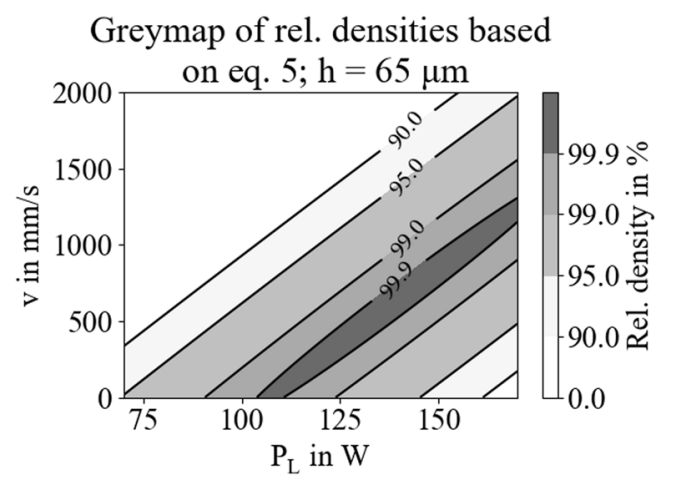

Fig. 7 Greymap of Eq. 5. The plot represents the regression based on the 72 specimens used to generate the empirical model and the 84 confirmation specimens and is therefore more precise. The hatch spacing is fixed to $65 \mu \mathrm{m}$

\subsection{Hardness tests}

The hardness of each printed specimen was determined using the Vickers hardness test according to EN ISO 65071:2018. Like the microstructure discussed above, the Vickers hardness (HV0.1) was not obviously influenced by different energy inputs or build-up rates. In contrast to the microstructure, the hardness has neither been influenced by the scanning pattern. The 18 tested specimens, manufactured with the pc which led to relative densities above $99.9 \%$ (c.f. Table 2), showed hardness values of $149 \pm 8$ HV0.1. These values are high compared with cold rolled niobium sheets which typically possess hardness values of approximately 50 HV0.1 [30]. An explanation for these high hardness values could be due to the high cooling rates which are typical in the PBF-LB/M process and the fine columnar microstructures achieved thereby [15, 31-33].

\subsection{Tensile tests}

The tensile test specimens were built with pc 4, 7, 10, 13 and 16 (c.f. Table 2). Accordingly, three sets of specimens, which were manufactured using relatively low build-up rates and thus high volume energies of approximately 260 $300 \mathrm{~J} / \mathrm{mm}^{3}$ (pc 7, 13, 16), one set with medium build-up rate and medium volume energy $\left(173.3 \mathrm{~J} / \mathrm{mm}^{3}, \mathrm{pc} 10\right)$ and one set with a high build-up rate (pc4) and low volume 
Fig. 8 Light microscope images of etched cross-sections, scanning paths are shown on top (rotated about $15^{\circ}$ around build direction). The sectioned level of $\mathbf{a}$ (pc17) has columnar (left of red line) and triangular growth (right of red line). Sectioned level of $\mathbf{b}$ (pc14) showed an inhomogeneous grain growth
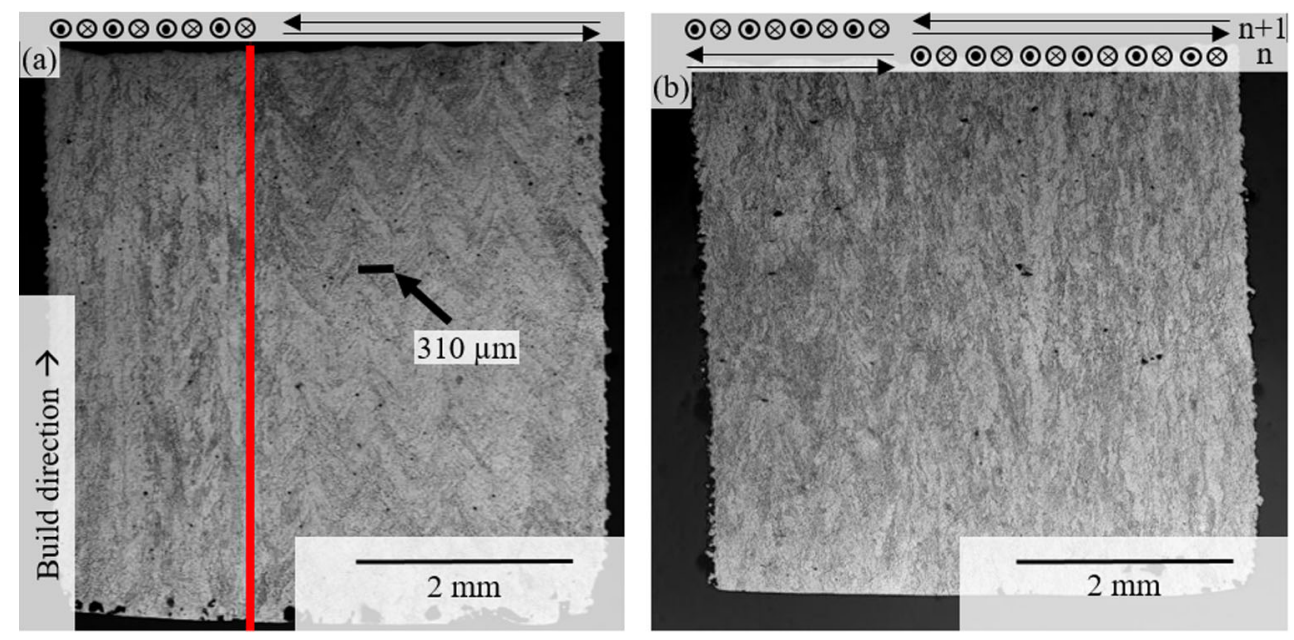

Fig. 9 Schematic illustration of wave-type grain orientation; a top view with scanning direction of two neighbouring scanning tracks; $\mathbf{b}$ bars which indicate the direction of heat conduction and grain orientation, as described in [23], with cut at the cross-sectioned plane of Fig. 8

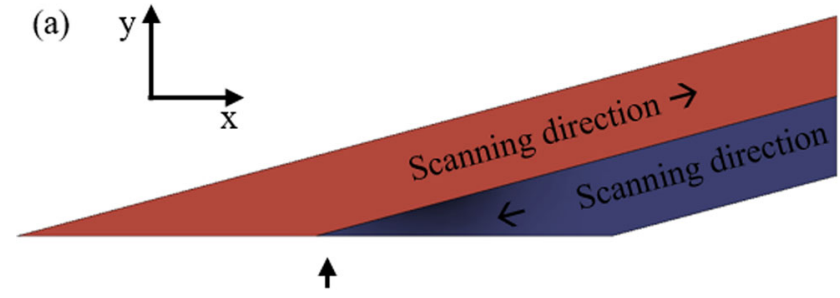

Cross section

(b)



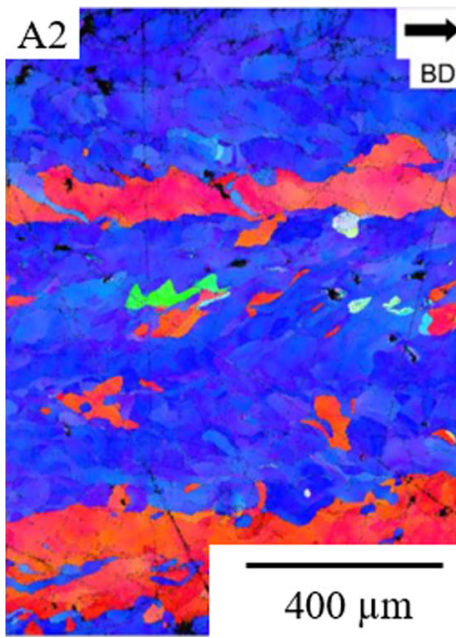
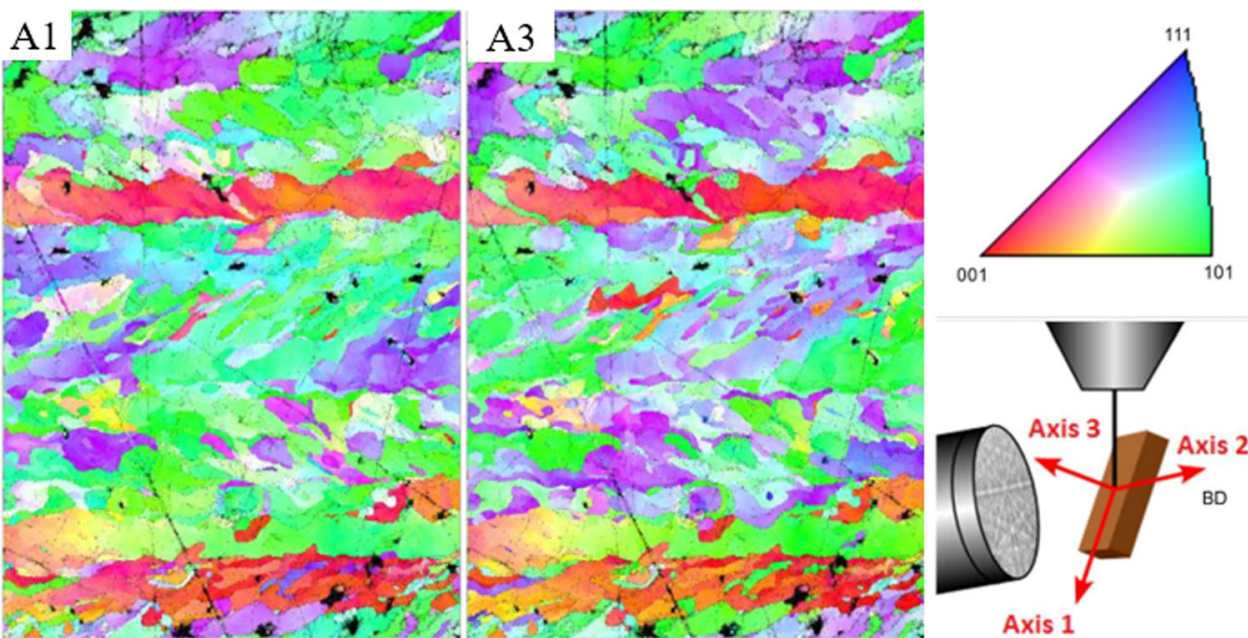

Fig. 10 EBSD images of pc 16 in the area of triangular grain growth (compare with Fig. 8a right side of image). Build direction (BD, A2) points from left to right, and the orientation of the axis is given on the right side 
Table 3 Results of tensile tests

\begin{tabular}{|c|c|c|c|c|c|}
\hline $\begin{array}{l}\text { Parameter com- } \\
\text { bination pc }\end{array}$ & $\begin{array}{l}\text { Build-up rate } B_{\mathrm{r}} \\
\text { in } \mathrm{mm}^{3} / \mathrm{s}\end{array}$ & $\begin{array}{l}\text { Volume energy } \\
E_{\mathrm{v}} \text { in } \mathrm{J} / \mathrm{mm}^{3}\end{array}$ & $\begin{array}{l}\text { Ultimate tensile } \\
\text { strength in MPa }\end{array}$ & $\begin{array}{l}\text { Yield strength } \\
\text { in } \mathrm{MPa}\end{array}$ & $\begin{array}{l}\text { Elongation at } \\
\text { break in } \%\end{array}$ \\
\hline 7 & 0.38 & 293.3 & $489 \pm 13$ & $310 \pm 10$ & $11.1 \pm 1.6$ \\
\hline 13 & 0.40 & 300.0 & $525 \pm 19$ & $316 \pm 25$ & $12.6 \pm 0.4$ \\
\hline 16 & 0.43 & 258.8 & $500 \pm 16$ & $309 \pm 4$ & $11.1 \pm 2.0$ \\
\hline 10 & 0.75 & 173.3 & $475 \pm 11$ & $309 \pm 11$ & $16.6 \pm 0.8$ \\
\hline $4 *$ & 1.63 & 104.6 & 444 & 324 & 8.3 \\
\hline
\end{tabular}

*Only one value

energy of approximately $105 \mathrm{~J} / \mathrm{mm}^{3}$ were considered for tensile testing. Three specimens of each pc were tested. Results for ultimate tensile strength (UTS), yield strength (YS) and elongation at break are given in Table 3. The bar charts provided in Fig. 11 indicate only minor differences in the determined values. Only a slight tendency of the UTS for lower values with increasing build-up rate or decreasing volume energy was observed. The highest value was $525 \pm 19 \mathrm{MPa}$ measured for pc $13\left(B_{\mathrm{r}}=0.4 \mathrm{~mm}^{3} / \mathrm{s}\right)$, while the lowest value corresponded to the highest buildup rate $\left(B_{\mathrm{r}}=1.63 \mathrm{~mm}^{3} / \mathrm{s}\right)$ with $\mathrm{pc} 4$ and $444 \mathrm{MPa}$. For pc 4 , only one value was available, because of an error

Fig. 11 Bar charts of ultimate tensile strength, yield strength and elongation at break in the order of increasing build-up rate. Bottom: Stress-strain diagrams of all tested specimen
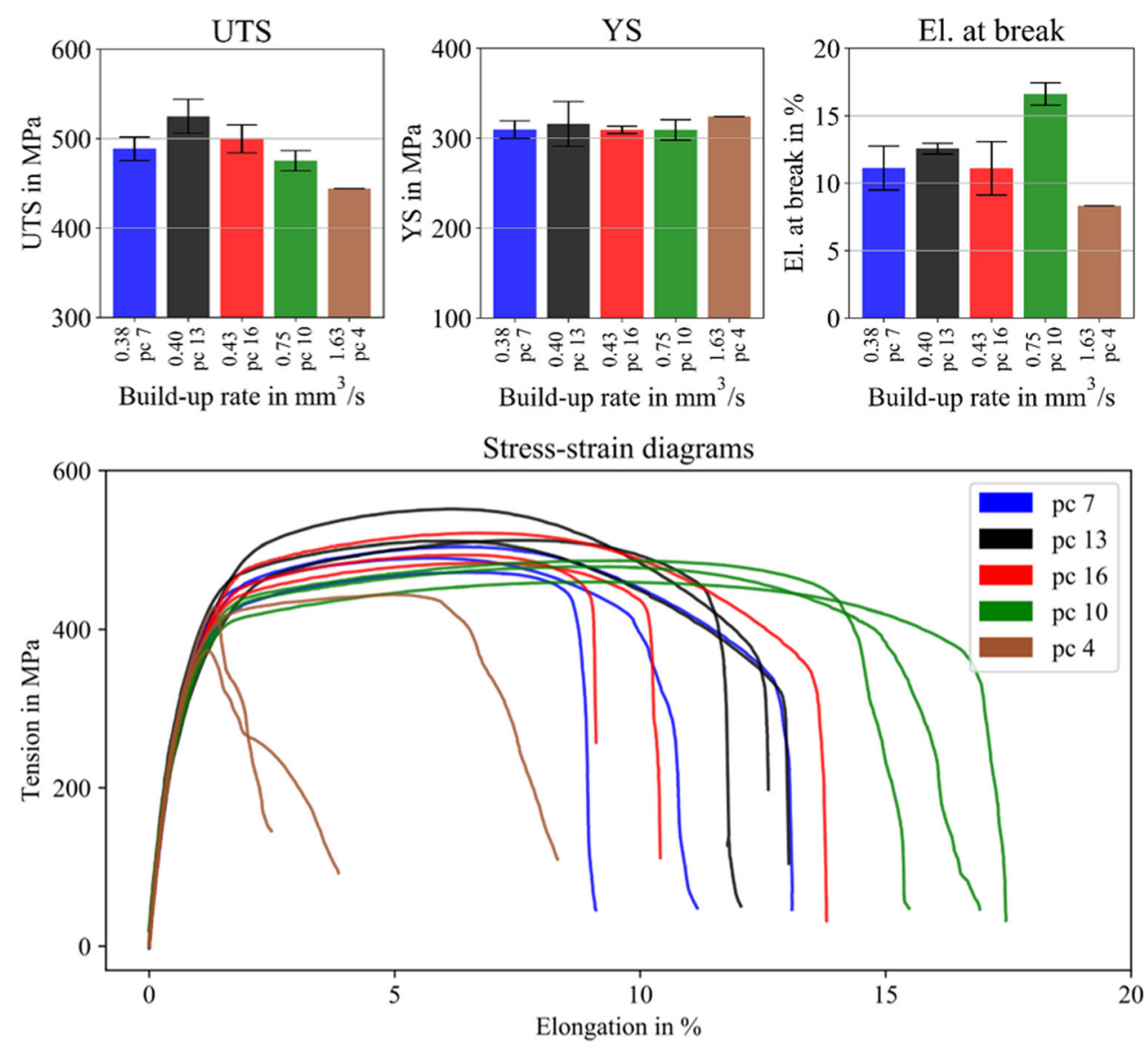

of the coating mechanism during the building process, which led to an early fracture in the tensile test. For the yield strength, no significant differences were observed. All values ranged slightly above $300 \mathrm{MPa}$. The values for UTS and YS were almost twice as high as for the reported electron beam-melted and wrought samples from Terrazas et al. [20]. It is known that the mechanical properties of niobium are affected by its oxygen content. For example, a niobium sheet containing $800 \mathrm{ppm}$ of oxygen has been reported to possess similar values for the UTS and YS as the specimens investigated in this study [34]. This could explain the high strength of PBF-LB/M processed niobium, 




Fig. 12 SEM images of fractured surfaces (pc 13). The overview b shows areas with ductile a and transgranular $\mathbf{c}$ fractured surfaces

taking into account that the starting powder had an oxygen content of approximately $556 \mathrm{ppm}$, which may further be increased during the PBF-LB/M process itself [35]. Another additional explanation is the long and fine grain shaped microstructure, typical for PBF-LB/M processed parts, which is caused by high cooling rates and thermal gradients, increasing the mechanical properties [36]. Grain shape and orientation are a possible reason for the relatively low elongation at break, which was approximately 8 to $16 \%$. Conventionally manufactured niobium, even with high oxygen content, has an elongation of about 40 to $50 \%$ [34], while niobium with long fine grains, manufactured by electron beam melting, showed similar values $<15 \%$ [37] compared with PBF-LB/M processed niobium. The SEM images of the fracture surfaces appeared more or less identical, suggesting a similar fracture behaviour of all five sets built using different pc. As an example, SEM images of pc 13 are illustrated in Fig. 12. The fractured
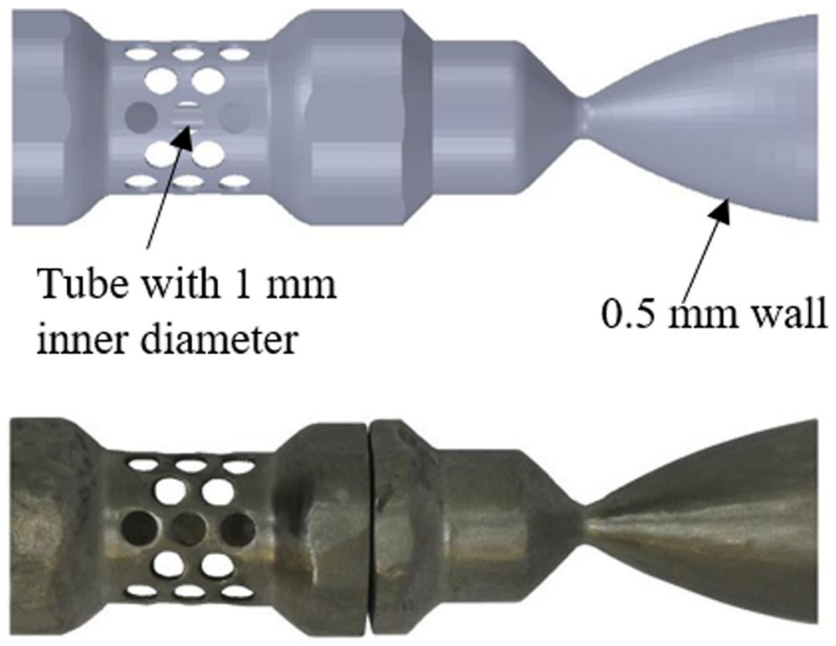

$20 \mathrm{~mm}$

Fig. 13 Construction of a navigation nozzle for satellites. Top: CAD model; bottom: PBF-LB/M/Nb manufactured part specimen is significantly necked as evident from Fig. 12(b). SEM images $12 \mathrm{a}$ and $12 \mathrm{c}$, which were recorded at a higher magnification, point to the presence of both ductile and transgranular brittle fracture behaviour, as there are areas with lamellar surface structures but also dimples. The surfaces suggesting ductile fracture have a higher proportion than those which appear transgranular. The presence of transgranular fracture could be an explanation for the low measured elongation at break as well.

\subsection{Demonstrator part}

Niobium and its alloys are potential materials for application in space or high temperature environment. To provide an example, the investigated parameter combination 7 and 10 were used to manufacture a design specimen of a navigation nozzle for satellites. The nozzle design was optimized for the additive manufacturing process and was manufactured in two parts. Those were assembled subsequently, as shown in Fig. 13. The design contained a $0.5-\mathrm{mm}$ curved wall and a tube with 1-mm inner diameter. Both pc led to successfully manufactured parts without obvious defects.

\section{Conclusion}

The present study describes an approach for the development of process parameter combinations ( $\mathrm{pc}$ ) for the additive manufacturing of spherical niobium powders by means of PBF-LB/M. The developed model allows a prediction of the process results considering a variation of process parameters such as laser power, scanning speed and hatch spacing. The described approach shall be principally adaptable to other materials than niobium discussed here. For PBF$\mathrm{LB} / \mathrm{M}$ processing of niobium, the following conclusions can be drawn:

- In a first step, a process field with 13 different pc has been investigated. Based on the results for the relative 
densities of the built specimens, an empirical model was fitted. Using this empirical model, 84 pc have been chosen, which should theoretically provide parts with relative densities $>99.9 \%$. The second step, the validation run of the $84 \mathrm{pc}$, resulted in specimens with at least $97 \%$ relative density. Eighteen pc actually led to parts with relative densities $>99.9 \%$. It can thus be assumed that the DoE approach is highly applicable to predict process results in this case.

- The build-up rates for the $18 \mathrm{pc}$ with relative densities $>99.9 \%$ varied from 0.33 to $1.63 \mathrm{~mm}^{3} / \mathrm{s}$. This provides a high potential for cost savings, especially in tightly packed build cycles with long laser scanning times in each layer.

- The microstructures of the manufactured parts depended on the direction of the scanning paths. Scanning paths nearly orthogonal to the cross-section resulted in vertically oriented columnar grains, while scanning paths nearly parallel to the section plane resulted in a triangular grain growth, caused by the direction of heat conduction.

- All tested specimens exhibited high Vickers hardness of approximately $150 \mathrm{HV} 0.1$. This is most probably attributed to high cooling rates occurring in PBF-LB/M and the associated formation of special fine and long grained microstructures.

- There were no significant differences detectable in the mechanical properties of niobium manufactured using different pc. Regarding UTS, there was only a slight trend observable: UTS was decreasing with higher build up rates or with lower volume energy input. However, all pc led to high values for both UTS and YS between 444 and $525 \mathrm{MPa}$ as well as $309 \mathrm{MPa}$ and $324 \mathrm{MPa}$, respectively. It can therefore be assumed that an increase of oxygen content during the process or powder atomization increased these values. The elongation at break was lower compared with conventionally processed niobium; the determined values are in the range of approximately 8 to $16 \%$. SEM investigations revealed the presence of both transgranular and ductile fracture. The simultaneous appearance of ductile and transgranular (brittle) fracture was most probably caused by the special morphology, i.e. relatively long and fine-shaped grains.

- The applicability of the investigated parameters has been shown through a design demonstrator of a navigation nozzle for satellites. No obvious defects were observed.

All in all, the hypothesis of a significant dependency of the mechanical properties on the built-up rate could not be confirmed within the scope of this trial. However, since the available laser power of the manufacturing equipment was limited to $170 \mathrm{~W}$, further investigations should be addressed using higher laser power and increased scanning speeds as well as powder bed thickness, improving the throughput, i.e. build-up rate and thus overall efficiency of the process. A variation of the hatching strategy might also influence the microstructure and properties of the manufactured part as it directly influences the direction of the heat conduction and thus the grain orientation.

Acknowledgements The authors would like to thank Prof. Dr. Thomas Niendorf (Institute of Materials Engineering, Universität Kassel, Germany) for providing the EBSD measurements. Further thank goes to Stefan Linke (Institute of Space Systems, Technische Universität Braunschweig, Germany) for providing the CAD-data for the demonstrator part.

\section{Author contribution}

Tjorben Griemsmann: conception; analysis; interpretation; visualisation; writing — original draft preparation

Arvid Abel: conception; execute trials; analysis; interpretation; visualization

Christian Hoff: writing - review and editing; supervision

Jörg Hermsdorf: writing — review and editing; supervision

Markus Weinmann: interpretation; writing-original draft preparation / review and editing

Stefan Kaierle: writing - review and editing; supervision

Funding Open Access funding enabled and organized by Projekt DEAL.

Data availability Data will be available upon request.

\section{Declarations}

Conflict of interest The authors declare no competing interests.

Open Access This article is licensed under a Creative Commons Attribution 4.0 International License, which permits use, sharing, adaptation, distribution and reproduction in any medium or format, as long as you give appropriate credit to the original author(s) and the source, provide a link to the Creative Commons licence, and indicate if changes were made. The images or other third party material in this article are included in the article's Creative Commons licence, unless indicated otherwise in a credit line to the material. If material is not included in the article's Creative Commons licence and your intended use is not permitted by statutory regulation or exceeds the permitted use, you will need to obtain permission directly from the copyright holder. To view a copy of this licence, visit http://creativecommons. org/licenses/by/4.0/.

\section{References}

1. Bauccio M (ed) (1994) ASM metals reference book, 3rd edn. ASM International, Materials Park

2. Deardo AJ (2003) Niobium in modern steels. Int Mater Rev 48(6):371-402. https://doi.org/10.1179/095066003225008833

3. Schwartz N, Gresh M, Karlik S (1961) Niobium solid electrolytic capacitors. J. Electrochem. Soc. 108(8):750. https://doi.org/10. $1149 / 1.2428210$ 
4. Ling HW, Kolski TL (1962) Niobium solid electrolyte capacitors. J. Electrochem. Soc. 109(1):69. https://doi.org/10.1149/ 1.2425333

5. Serjak W, Schechter L, Tripp T, Lanin L, Reichert K, Thomas VJ (2000) Niobium, a new material for capacitors. Passive Component Industry, pp 17-20

6. Finnemore DK, Stromberg TF, Swenson CA (1966) Superconducting properties of high-purity niobium. Phys Rev 149(1):231243. https://doi.org/10.1103/PhysRev.149.231

7. Autler SH, Rosenblum ES, Gooen KH (1962) High-field superconductivity in niobium. Phys. Rev. Lett. 9(12):489-493. https://doi.org/10.1103/PhysRevLett.9.489

8. Scanlan RM, Malozemoff AP, Larbalestier DC (2004) Superconducting materials for large scale applications. Proc. IEEE 92(10):1639-1654. https://doi.org/10.1109/JPROC.2004.833673

9. Aimone P, Yang M (2018) Niobium alloys for the chemical process industry. Int J Refract Met Hard Mater 71:335-339. https://doi.org/10.1016/j.ijrmhm.2017.11.036

10. Gupta C, Suri A (1994) Properties and applications of niobium. In: Extractive metallurgy of niobium, Routledge, chap 1, https:// www.taylorfrancis.com/books/9781351448970

11. Suri AK (1993) Extractive metallurgy of niobium, 1st edn. CRC Press, Bosa Roca

12. Yap CY, Chua CK, Dong ZL, Liu ZH, Zhang DQ, Loh LE, Sing SL (2015) Review of selective laser melting: materials and applications. Appl Phys Rev 2(4):041101. https://doi.org/10.1063/ 1.4935926

13. Fischer M, Joguet D, Robin G, Peltier L, Laheurte P (2016) In situ elaboration of a binary $\mathrm{Ti}-26 \mathrm{Nb}$ alloy by selective laser melting of elemental titanium and niobium mixed powders. Mater. Sci. Eng. C 62:852-859. https://doi.org/10.1016/j.msec.2016.02.033

14. Guo Y, Jia L, Kong B, Wang N, Zhang H (2018) Single track and single layer formation in selective laser melting of niobium solid solution alloy. Chinese J. Aeronaut 31(4):860-866. https://doi.org/10.1016/j.cja.2017.08.019 M4

15. Guo Y, Jia L, Sun S, Kong B, Liu J, Zhang H (2016) Rapid fabrication of $\mathrm{Nb}-\mathrm{Si}$ based alloy by selective laser melting: microstructure, hardness and initial oxidation behavior. Mater Des 109:37-46. https://doi.org/10.1016/j.matdes.2016.07.048

16. Wang Q, Han C, Choma T, Wei Q, Yan C, Song B, Shi $\mathrm{Y}$ (2017) Effect of $\mathrm{Nb}$ content on microstructure, property and in vitro apatite-forming capability of $\mathrm{Ti}-\mathrm{Nb}$ alloys fabricated via selective laser melting. Mater. Des. 126:268-277. https://doi.org/10.1016/j.matdes.2017.04.026

17. Sharkeev YP, Eroshenko AY, Kovalevskaya ZG, Saprykin AA, Ibragimov EA, Glukhov IA, Khimich MA, Uvarkin PV, Babakova EV (2016) Structural and phase state of Ti-Nb alloy at selective laser melting of the composite powder. Russian Phys J 59(3):430 434. https://doi.org/10.1007/s11182-016-0790-z

18. Schulze C, Weinmann M, Schweigel C, Keßler O, Bader R (2018) Mechanical properties of a newly additive manufactured implant material based on Ti-42Nb. Materials 11(1):124 https://doi.org/10.3390/ma11010124

19. Zhang S, Cheng X, Yao Y, Wei Y, Han C, Shi Y, Wei Q, Zhang Z (2015) Porous niobium coatings fabricated with selective laser melting on titanium substrates: preparation, characterization, and cell behavior. Mater Sci Eng C 53:50-59. https://doi.org/10.1016/j.msec.2015.04.005

20. Terrazas CA, Mireles J, Gaytan SM, Morton PA, Hinojos A, Frigola P, Wicker RB (2015) Fabrication and characterization of high-purity niobium using electron beam melting additive manufacturing technology. Int J Adv Manuf Technol 60:96. https://doi.org/10.1007/s00170-015-7767-x M4

21. Martinez E, Murr LE, Hernandez J, Pan X, Amato K, Frigola P, Terrazas C, Gaytan S, Rodriguez E, Medina F, Wicker RB (2013)
Microstructures of niobium components fabricated by electron beam melting. Metallography, Microstructure, and Analysis 2(3):183-189. https://doi.org/10.1007/s13632-013-0073-9

22. Vrancken B, Thijs L, Kruth JP, van Humbeeck J (2012) Heat treatment of Ti6Al4V produced by selective laser melting. J Alloys Compounds 541:177-185. https://doi.org/10.1016/j.jallcom.2012. 07.022

23. Thijs L, Verhaeghe F, Craeghs T, van Humbeeck J, Kruth JP (2010) A study of the microstructural evolution during selective laser melting of Ti-6Al-4V. Acta Mater. 58(9):3303-3312. https://doi.org/10.1016/j.actamat.2010.02.004

24. Read N, Wang W, Essa K, Attallah MM (2015) Selective laser melting of AlSi10Mg alloy. Materials \&, Design (1980-2015) 65:417-424. https://doi.org/10.1016/j.matdes.2014.09.044

25. Tolosa I, Garciandía F, Zubiri F, Zapirain F, Esnaola A (2010) Study of mechanical properties of AISI 316 stainless steel processed by "selective laser melting", following different manufacturing strategies. Int J Adv Manuf Technol 51(5):639647. https://doi.org/10.1007/s00170-010-2631-5

26. Carter LN, Martin C, Withers PJ, Attallah MM (2014) The influence of the laser scan strategy on grain structure and cracking behaviour in SLM powder-bed fabricated nickel superalloy. J Alloys Compounds 615:338-347. https://doi.org/10.1016/x 2014.06.172

27. Niendorf $T$, Leuders S, Riemer A, Richard HA, Tröster $T$, Schwarze D (2013) Highly anisotropic steel processed by selective laser melting. Metallurgical and Materials Transactions B 44(4):794-796. https://doi.org/10.1007/s11663-013-9875-z

28. TANIOBIS GmbH (2021) AMtrinsic $\AA$ spherical Nb powder for additive manufacturing. https://www.taniobis.com/ settings/file/85a37c136d638b02016da69c39921512.de.0/flyer \%20nb_taniobis_2020.pdf

29. Kasperovich G, Haubrich J, Gussone J, Requena G (2016) Correlation between porosity and processing parameters in TiAl6V4 produced by selective laser melting. Mater Des 105:160 170. https://doi.org/10.1016/j.matdes.2016.05.070

30. Terricabras AG, Carvalho AA, Santillana IA, Barrière S, Calaga $\mathrm{R}$, Cano-Pleite E, Capatina O, Crouvizier MD, Dassa L, Meyer MS (2019) Assessment of the mechanical properties of ultra-high purity niobium after cold work and heat treatment with the HL-LHC crab cavities as benchmark. 19th International Conference on RF Superconductivity, pp 862-867 https://doi.org/10.18429/JACoW-SRF2019-THP012

31. Buchbinder D, Schleifenbaum $H$, Heidrich S, Meiners $W$, Bültmann J (2011) High power selective laser melting (HP SLM) of aluminum parts. Phys Procedia 12:271-278. https://doi.org/10. 1016/j.phpro.2011.03.035

32. Aboulkhair NT, Maskery I, Tuck C, Ashcroft I, Everitt NM (2016) The microstructure and mechanical properties of selectively laser melted AlSil0Mg: The effect of a conventional T6-like heat treatment. Mater Sci Eng A 667:139-146. https://doi.org/10.1016/j.msea.2016.04.092

33. Sander J, Hufenbach J, Giebeler L, Wendrock H, Kühn U, Eckert J (2016) Microstructure and properties of FeCrMoVC tool steel produced by selective laser melting. Mater Des 89:335-341. https://doi.org/doi.org/10.1016/j.matdes.2015.09.148

34. Sankar M, Baligidad RG, Gokhale AA (2013) Effect of oxygen on microstructure and mechanical properties of niobium. Mater Sci Eng A 569:132-136. https://doi.org/10.1016/j.msea.2013.01.025

35. Hagemann R, Noelke C, Rau T, Kaierle S, Overmeyer L, Wesling V, Wolkers W (2015) Design, processing, and characterization of nickel titanium micro-actuators for medical implants. J Laser Appl 27:S29203 
36. Shunmugavel M, Polishetty A, Littlefair G (2015) Microstructure and mechanical properties of wrought and additive manufactured Ti-6Al-4V cylindrical bars. Procedia Technology 20:231-236. https://doi.org/10.1016/j.protcy.2015.07.037 M4

37. Ermakov A, Jelezov I, Singer $X$, Singer W, Viswanathan GB, Levit V, Fraser HL, Wen H, Spiwek M (2008) Physical properties and structure of large grain/single crystal niobium for superconducting RF cavities. J Phys Conference Ser 97:12014. https://doi.org/10.1088/1742-6596/97/1/012014

Publisher's note Springer Nature remains neutral with regard to jurisdictional claims in published maps and institutional affiliations. 